Fixed Point Theory, 22(2021), No. 1, 263-278

DOI: $10.24193 /$ fpt-ro.2021.1.19

http://www.math.ubbcluj.ro/ nodeacj/sfptcj.html

\title{
MOMENTS SOLUTION OF FRACTIONAL EVOLUTION EQUATION FOUND BY NEW KRASNOSELSKII TYPE FIXED POINT THEOREMS
}

\author{
HEMANT KUMAR NASHINE*, RABHA W. IBRAHIM** AND RAVI P. AGARWAL*** \\ * Department of Mathematics, School of Advanced Sciences, \\ Vellore Institute of Technology, Vellore, Tamil Nadu, India \\ Department of Mathematics and Applied Mathematics, \\ University of Johannesburg, Auckland Park 2006, South Africa \\ E-mail: drhknashine@gmail.com, hemant.nashine@vit.ac.in \\ ** Informetrics Research Group, Ton 1Duc Thang University, Ho Chi Minh City, Vietnam \\ and \\ Faculty of Mathematics \& Statistics, Ton Duc Thang University, Ho Chi Minh City, Vietnam \\ E-mail: rabhaibrahim@tdtu.edu.vn \\ *** Department of Mathematics, Texas A \& M University - Kingsville, TX, USA \\ E-mail: ravi.agarwal@tamuk.edu \\ and \\ Distinguished University Professor of Mathematics, \\ Florida Institute Of Technology, Melbourne, FL 32901, USA
}

\begin{abstract}
In this note, we establish the existence of solutions in the moment mode of a fractional evolution equation, as well as a fractional coupled system, obtained by new Krasnoselskii type fixed point and coupled fixed point theorems. We use new Krasnoselskii type contraction conditions in the sense of measure of noncompactness in Banach spaces. The new outcomes extend some special well known recent results.

Key Words and Phrases: Hybrid fixed point theorem, coupled fixed point theorem, measure of noncompactness, fractional differential equation, fractional calculus, fractional differential operator. 2020 Mathematics Subject Classification: 35K90, 47H10, 44A45.
\end{abstract}

\section{REFERENCES}

[1] A. Aghajani, R. Allahyari, M. Mursaleen, A generalization of Darbo's theorem with application to the solvability of systems of integral equations, J. Comput. Appl. Math., 260(2014), 68-77.

[2] A. Aghajani, J. Banas, Y. Jalilian, Existence of solution for a class of nonlinear Volterra singular integral equations, Comp. Math. Appl., 62(2011), 1215-1227.

[3] A. Aghajani, J. Banas, N. Sabzali, Some generalizations of Darbo fixed point theorem and applications, Bull. Belg. Math. Soc. Simon Stevin., 20(2013), no. 2, 345-358.

[4] A. Aghajani, N. Sabzali, A coupled fixed point theorem for condensing operators with application to system of integral equations, J. Nonlinear Convex Anal., 15(2014), 941-952.

[5] J. Appell, Implicit functions, nonlinear integral equations, and the measure of noncompactness of the superposition operator, J. Math. Anal. Appl., 83(1981), 251-263. 
[6] J. Appell, Measure of noncompactness, condensing operators and fixed points: An application oriented survey, Fixed Point Theory, 6(2005), 157-229.

[7] J. Appell, M.P. Pera, Noncompactness principles in nonlinear operator approximation theory, Pacific J. Math., 115(1984), 13-31.

[8] R. Arab, Some fixed point theorems in generalized Darbo fixed point theorem and the existence of solutions for system of integral equations, J. Korean Math. Soc., 52(2015), 125-139.

[9] R. Arab, The existence of fixed points via the measure of noncompactness and its application to functional-integral equations, Mediterr. J. Math., 13(2016), 759-773.

[10] D. Baleanu, J. Machado, C.J. Luo Albert, Fractional Dynamics and Control, Springer Science \& Business Media, 2011

[11] J. Banas, Measures of noncompactness in the space of continuous tempered functions, Demonstr. Math., 14(1981), 127-133.

[12] J. Banas, On measures of noncompactness in Banach Spaces, Comment. Math. Univ. Carolinae, 21.1(1980), 131-143.

[13] J. Banas, K. Goebel, Measures of Noncompactness in Banach Spaces, Lecture Notes in Pure and Applied Mathematics, Dekker, New York, 1980, p. 60.

[14] T.A. Burton, Krasnoselskii's inversion principle and fixed points, Nonlinear Analysis, 30(1997), 3975-3986.

[15] T.A. Burton, C. Kirk, A fixed point theorem of Krasnoselskii-Schaefer type, Mathematische Nachrichten, 189(1998), 23-31.

[16] G. Darbo, Punti uniti transformazion a condominio non compatto, Rend. Sem. Math. Univ. Padova, 4(1995), 84-92.

[17] B.C. Dhage, S.B. Dhage, H.K. Pathak, A generalization of Darbo's fixed point theorem and local attractivity of generalized nonlinear functional integral equations, Differ. Eq. Appl., 7(2015), 5777.

[18] M. Geraghty, On contractive mappings, Proc. Amer. Math. Soc., 40(1973), 604-608.

[19] D. Guo, V. Lakshmikantham, X. Liu, Nonlinear Integral Equations in Abstract Spaces, Kluwer Academic Publishers, Dordrecht, 1996.

[20] R.W. Ibrahim, Fractional Calculus of Multi-objective Functions \& Multi-agent Systems, Lambert Academic Publishing, Saarbrucken, Germany, 2017.

[21] S. Ishikawa, Fixed points by a new iteration, Proc. Amer. Math. Soc., 73(1974), 147-150.

[22] A.A. Kilbas, H.M. Srivastava, J.J. Trujillo, Theory and Applications of Fractional Differential Equations, North-Holland, Mathematics Studies, Elsevier, 2006.

[23] N. Mizoguchi, W. Takahashi, Fixed point theorems for multivalued mappings on complete metric spaces, J. Math. Anal. Appl., 141(1989), no. 1, 177-188.

[24] M. Mursaleen, A. Alotaibi, Infinite system of differential equations in some spaces, Abstr. Appl. Anal., (2012), art. ID 863483, 20 pages.

[25] M. Mursaleen, S.A. Mohiuddine, Applications of measures of noncompactness to the infinite system of differential equations in $l_{p}$ spaces, 75(2012), 2111-2115.

[26] H.K. Nashine, R. Arab, R.P. Agarwal, A.S. Haghighi, Darbo type fixed and coupled fixed point results and its application to integral equation, Periodica Mathematica Hungarica, 77(2018), 94-107.

[27] S. Reich, Constructive techniques for accretive and monotone operators, in: Applied Nonlinear Analysis (V. Lakshmikantham, Ed.), Academic Press, New York, 1979, 335-345.

[28] I.A. Rus, A. Petruşel, G. Petruşel, Fixed Point Theory: 1950 - 2000, Romanian Contribution, House of the Book of Science, Cluj-Napoca, 2002.

[29] H. Yang, E. Ibrahim, J. Ma, Hybrid fixed point theorems with application to fractional evolution equations, J. Fixed Point Theory Appl., 19(2017), no. 4, 2663-2679.

Received: June 7, 2018; Accepted: July 15, 2018. 
